\title{
Biosynthesis of Silver Nanoparticles from Desmodium triflorum: A Novel Approach Towards Weed Utilization
}

\author{
Naheed Ahmad, ${ }^{1}$ Seema Sharma, ${ }^{2}$ V. N. Singh, ${ }^{3}$ S. F. Shamsi, ${ }^{4}$ Anjum Fatma, ${ }^{5}$ and B. R. Mehta ${ }^{3}$ \\ ${ }^{1}$ Department of Botany, Patna University, Patna 800013, India \\ ${ }^{2}$ Department of Physics, A.N.College, Patna 800013, India \\ ${ }^{3}$ Thin Film Laboratory, Department of Physics, Indian Institute of Technology, New Delhi 110015, India \\ ${ }^{4}$ Department of Electrical and Electronic Engineering, SMIT, Sikkim, India \\ ${ }^{5}$ Department of Chemistry, Magadh Mahila College, Patna University, Patna 800013, India
}

Correspondence should be addressed to Seema Sharma, seema_sharma26@yahoo.com

Received 17 May 2010; Revised 14 July 2010; Accepted 19 August 2010

Academic Editor: Gabriel A. Monteiro

Copyright (C) 2011 Naheed Ahmad et al. This is an open access article distributed under the Creative Commons Attribution License, which permits unrestricted use, distribution, and reproduction in any medium, provided the original work is properly cited.

\begin{abstract}
A single-step environmental friendly approach is employed to synthesize silver nanoparticles. The biomolecules found in plants induce the reduction of $\mathrm{Ag}^{+}$ions from silver nitrate to silver nanoparticles (AgNPs). UV-visible spectrum of the aqueous medium containing silver ions demonstrated a peak at $425 \mathrm{~nm}$ corresponding to the plasmon absorbance of silver nanoparticles. Transmission electron microscopy (TEM) showed the formation of well-dispersed silver nanoparticles in the range of 5-20 nm. Xray diffraction (XRD) spectrum of the AgNPs exhibited $2 \theta$ values corresponding to the silver nanocrystal. The process of reduction is extracellular and fast which may lead to the development of easy biosynthesis of silver nanoparticles. Plants during glycolysis produce a large amount of $\mathrm{H}^{+}$ions along with NAD which acts as a strong redoxing agent; this seems to be responsible for the formation of AgNPs. Water-soluble antioxidative agents like ascorbic acids further seem to be responsible for the reduction of AgNPs. These AgNPs produced show good antimicrobial activity against common pathogens.
\end{abstract}

\section{Introduction}

Nanoparticles with controlled size and composition are of fundamental and technological interest as they provide solutions to technological and environmental challenges in the areas of solar energy conversion, catalysis, medicine, and water treatment. Thus, production and application of nanomaterials from 1 to 100 nanometers $(\mathrm{nm})$ is an emerging field of research $[1,2]$. Global warming and climate change have induced a worldwide awareness and effort to reduce generated hazardous wastes. Thus, "Green" chemistry and chemical processes are progressively being integrated in science and industry for sustainable development [3].

Nanomaterials due to their sheer size show unique and considerably changed physical, chemical, and biological properties compared to their macro scale counterparts [4]. Gold, silver, and copper have been used mostly for the synthesis of stable dispersions of nanoparticles, which are useful in areas of photography, catalysis, biological labeling, photonics, optoelectronics, and surface-enhanced Raman scattering (SERS) detection [5-7].

Biological methods are considered safe and ecologically sound for the nanomaterial fabrication as an alternative to conventional physical and chemical methods. Biological routes to the synthesis of these particles have been proposed by exploiting microorganisms [8-12] and by vascular plants [13-22]. The functions of these materials depend on their composition and structure. Plants have been reported to be used for synthesis of metal nanoparticles of gold and silver and of a gold-silver-copper alloy [13-22]. Colloidal silver is of particular interest because of its distinctive properties such as good conductivity, chemical stability, and catalytic and antibacterial activity [23-25].

India has great potential for bioprospecting because of its rich biodiversity. Advances in biotechnology have increased the value of plant genetic resources. Leguminous plants 


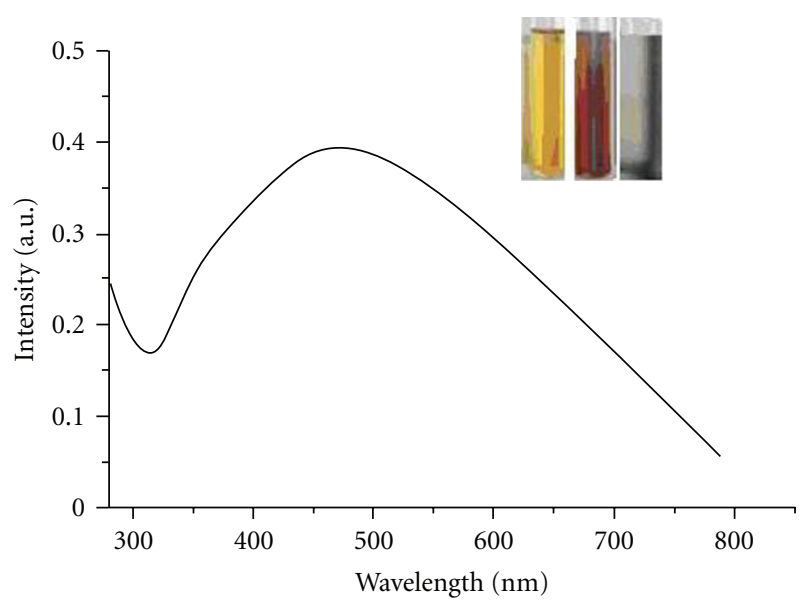

FIgURE 1: UV/Vis spectra recorded from the culture supernatant that shows the production of AgNPs after 24 hours of reaction. Inset photograph shows change in colour after adding $\mathrm{AgNO}_{3}$, (a) after 5 minutes, (b) after 20 minutes and (c) 1 hour.

possess important natural products and phytochemicals that are useful as industrial, medicinal, and agricultural raw materials. However, most of these legume species have not been fully exploited for their chemical or biologically active components. One of the largest tropical wild species of legume is Desmodium, with Southeast Asia as an important centre of species diversification. The genus Desmodium Desv. nom. cons (Fabaceae) has a worldwide distribution and consists of over 300 species with 67 species native to India [26]. The genus has proved to be important in possessing various phytochemicals. The chemical literature $[26,27]$ reveals that the species Desmodium triflorum are rich in polyphenols, flavonoids, sterols, triterpenes, and reducing sugars in all extracts. The plants are also used extensively in traditional medicine.

Studies have indicated that biomolecules like protein, phenols, and flavonoids not only play a role in reducing the ions to the nanosize, but also play an important role in the capping of the nanoparticles [28-30]. The reduction of $\mathrm{Ag}^{+}$ions by combinations of biomolecules found in these extracts such as vitamins, enzymes/proteins, organic acids such as citrates, amino acids, and polysaccharides [29-31] is environmentally benign, yet chemically complex.

We have looked at the composition of other plants for possible presence of such molecules and have identified Desmodium plants as a potential candidate for synthesis of silver nanoparticles [31]. Extracts from this plant may act both as reducing and capping agents in AgNPs synthesis. This paper demonstrates that the reaction of aqueous silver ions with Desmodium triflorum extract resulted in the extracellular formation of AgNPs at room temperature which was further harvested by simple heat drying evaporation. As most of the bacteria have developed resistance to antibiotics there is a need for an alternative antibacterial substance [32]. Silver is known for its antimicrobial properties and has been used for years in the medical field for antimicrobial applications and even has shown to prevent HIV binding to host cells [33-35]. The AgNPs are also reported to be nontoxic to human and most effective against bacteria, viruses, and other eukaryotic micro-organisms at very low concentration and without any side effects [36]. We have also made an attempt to find out the use of these bioprospected plant-mediated synthesized AgNPs as possible antimicrobial agents. Silver nanoparticles may have an important advantage over conventional antibiotics in that they kill all pathogenic microorganisms, and no organism has ever been reported to readily develop resistance to it.

\section{Results and Discussion}

2.1. Addition of the Plant Broth to the $10^{3} \mathrm{M}$ Aqueous $\mathrm{AgNO}_{3}$ Resulted in Change of Colour within Minutes (inset Figure 1). The signatory tea-brown color was obtained which resulted due to the excitation of the Surface Plasmon Resonance (SPR) vibrations of the silver nanoparticles formed. The reaction could easily be tracked by the change in color and reconfirmed by UV-Vis spectroscopy.

Figure 1 shows UV-Vis spectra of the aqueous plant extracts with $\mathrm{AgNO}_{3}(0.025 \mathrm{M})$ solution. The weak absorption peak at $200 \mathrm{~nm}$ (not shown here) indicates the presence of several organic compounds which are known to interact with silver ions. An absorption band at $270 \mathrm{~nm}$ is attributed to the aromatic amino acids of proteins. It is well known that the absorption band at $270 \mathrm{~nm}$ arises due to electronic excitations in tryptophan and tyrosine residues in the proteins. This observation indicates the release of proteins into solution by Desmodium triflorum and suggests a possible mechanism for the reduction of the metal ions present in the solution. Disturbances in the 200-320 nm were observed after 1 hour of the reaction probably indicating that the capping occurs after the reduction of the silver nanoparticles. The samples display an optical absorption band peaked at about $420 \mathrm{~nm}$, typical of absorption for metallic $\mathrm{Ag}$ nanoclusters, due to the Surface Plasmon Resonance (SPR), which increased with time till about three hours of reaction period. Plasmon bands are broad with an absorption tail in the longer wavelengths. The cause of the infrared absorption is the stretching vibration within the molecule and could be due to the presence of $\mathrm{N}_{2}, \mathrm{H}_{2}, \mathrm{C}$, and $\mathrm{O}_{2}$ bonds. In principle it could be due to the excitation of the in-plane SPR and probably indicate significant anisotropy in the shape of nanoparticles.

\subsection{Plants Contain a Complex Network of Antioxidant} Metabolites and Enzymes That Work together to Prevent Oxidative Damage to Cellular Components. Isolated quercetin [37] and polysaccharides [28-31] have been used for the synthesis of silver nanoparticles. Desmodium is reported to contain chemically different groups of compounds: polyphenols, flavonoids, sterols, triterpenes, triterpenoid saponins, beta-phenylethylamines, tetrahydroisoquinolines, reducing sugars like glucose and fructose, and proteins, in all extracts. The plant extract is reported to have activities of scavenging superoxide anion radicals and 1, 1diphenyl-2-picrylhydrazyl radicals (DPPH). It could be that 

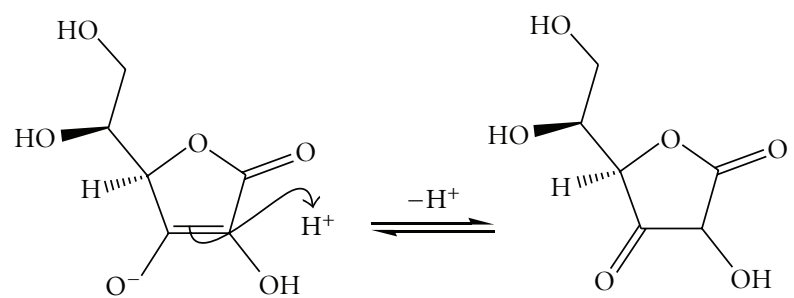

Ascorbic acid

Ascorbate radical

$$
\begin{aligned}
\mathrm{AgNO}_{3} & \longrightarrow \mathrm{Ag}^{+}+\mathrm{NO}_{3}^{-} \\
\mathrm{Ag}^{+}+\mathrm{e}^{-} & \longrightarrow \mathrm{Ag}^{0}
\end{aligned}
$$

SCheme 1

these water-soluble scavenging superoxide anion radicals and 1, 1-diphenyl-2-picrylhydrazyl (DPPH) radicals present in the plant extract be responsible for the reduction of silver and synthesis of nanoparticles through biogenic routes. The exact mechanism of the formation of these nanoparticles in these biological media is unknown. Presumably, biosynthetic products or reduced cofactors play an important role in the reduction of respective salts to nanoparticles. However, it seems probable that some glucose and ascorbate reduce $\mathrm{AgNO}_{3}$ to form nanoparticles.

The probability of reduction of $\mathrm{AgNO}_{3}$ to silver may be illustrated due to the mechanism known as glycolysis. Plants fix $\mathrm{CO}_{2}$ in presence of sunlight. Carbohydrates are the first cellular constituent formed by the photosynthesizing organism on absorption of light. This carbohydrate is utilized by the cell as glucose by Glycolysis. This is the metabolic pathway that converts glucose $\mathrm{C}_{6} \mathrm{H}_{12} \mathrm{O}_{6}$ into pyruvate and hydrogen ion:

$$
\mathrm{CH} 3 \mathrm{COCOO}^{-}+\mathrm{H}^{+} \text {. }
$$

The free energy released in this process is used to form the high-energy compounds, ATP adenosine triphosphate and NADH (reduced nicotinamide adenine dinuleotide). Glycolysis can be represented by the following simple equation:

$$
\begin{aligned}
& \text { Glucose }+2 \mathrm{ADP}+2 \mathrm{Pi}+2 \mathrm{NAD}^{+} \\
& =2 \text { Pyruvate }+2 \mathrm{ATP}+2 \mathrm{NADH}+2 \mathrm{H}^{+} .
\end{aligned}
$$

Glycolysis is a definite sequence of ten reactions involving ten intermediate compounds (Figure 2). Large amount of $\mathrm{H}^{+}$ ions are produced along with ATP.

Nicotinamide adenine dinucleotide, abbreviated $\mathrm{NAD}^{+}$, is a coenzyme found in all living cells. NAD is a strong reducing agent. $\mathrm{NAD}^{+}$is involved in redox reactions, carrying electrons from one reaction to another. The coenzyme is therefore found in two forms in cells. $\mathrm{NAD}^{+}$is an oxidising agent-it accepts electrons from other molecules and becomes reduced. This reaction forms $\mathrm{NADH}$, which can donate electrons. These electron transfer reactions are the main function of NAD:

$$
\begin{gathered}
\mathrm{AgNO}_{3} \longrightarrow \mathrm{Ag}^{+}+\mathrm{NO}_{3}, \\
\mathrm{NAD}^{+}+\mathrm{e} \longrightarrow \mathrm{NAD}, \\
\mathrm{NAD}+\mathrm{H}^{+} \longrightarrow \mathrm{NADH}+\mathrm{e}^{-}, \\
\mathrm{e}^{-}+\mathrm{Ag}^{+} \longrightarrow \mathrm{Ag}^{0}
\end{gathered}
$$

$\mathrm{NAD}^{+}$keeps on getting reoxidised and gets constantly regenerated due to redox reactions. This might have led to transformations of $\mathrm{Ag}$ ions to $\mathrm{Ag}^{0}$.

Another mechanism for the reduction of Ag ions to silver could be due to the presence of water-soluble antioxidative substances like ascorbate. This acid is present at high levels in all parts of plants. Ascorbic acid is a reducing agent and can reduce, and thereby neutralize, reactive oxygen species leading to the formation of ascorbate radical and an electron. This free electron reduces the $\mathrm{Ag}^{+}$ion to $\mathrm{Ag}^{0}$ (Scheme 1) .

2.3. It Is Important to Know the Exact Nature of the Silver Particles Formed, and This Can Be Deduced from the XRD Spectrum of the Sample.. XRD pattern of derived AgNPs (Figure 3) shows four intense peaks in the whole spectrum of $2 \Theta^{\circ}$ values ranging from $20^{\circ}$ to $70^{\circ}$. XRD spectra of pure crystalline silver structures have been published by the Joint Committee on Powder Diffraction Standards (file no. 04-0783). A comparison of our XRD spectrum with the Standard confirmed that the silver particles formed in our experiments were in the form of nanocrystals, as evidenced by the peaks at $2 \Theta$ values of $38.45^{\circ}, 44.48^{\circ}$, $64.69^{\circ}$, and $77.62^{\circ}$, corresponding to [111], [200], [220], and [311] planes for silver, respectively. Moreover, two small insignificant impurity peaks are observed at $68^{\circ}$ and $75^{\circ}$ which may be attributed to the presence of other organic substances in culture supernatant.

Scherrer's equation for broadening resulting from a small crystalline size, the mean, effective, or apparent dimension of the crystall composing the powder is

$$
P_{\mathrm{hkl}}=k \lambda / \beta 1 / 2 \cos \Theta,
$$

where $\Theta$ is the Bragg angle, $\lambda$ is the wavelength of the $\mathrm{X}$ ray used, $\beta$ is the breadth of the pure diffraction profile in radians on $2 \Theta$ scale, and $k$ is a constant approximately equal to unity and related both to the crystalline shape and to the way in which $\Theta$ is defined. The best possible value of $k$ has been estimated as 0.89 . The Full Width at Half Maximum (FWHM) values measured for [111], [200], [220], and [311] planes of reflection were used with the Debye-Scherrer equation (4) to calculate the size of the nanoparticles.

Further analysis of the silver particles by Energydispersive spectroscopy confirmed the presence of the signal characteristic of silver. Figure 4 shows the Energy-Dispersive Absorption Spectroscopy photographs of derived AgNPs.

All the peaks of Ag are observed and are assigned. Peaks for $\mathrm{Cu}$ and $\mathrm{C}$ are from the grid used, and the peaks for 


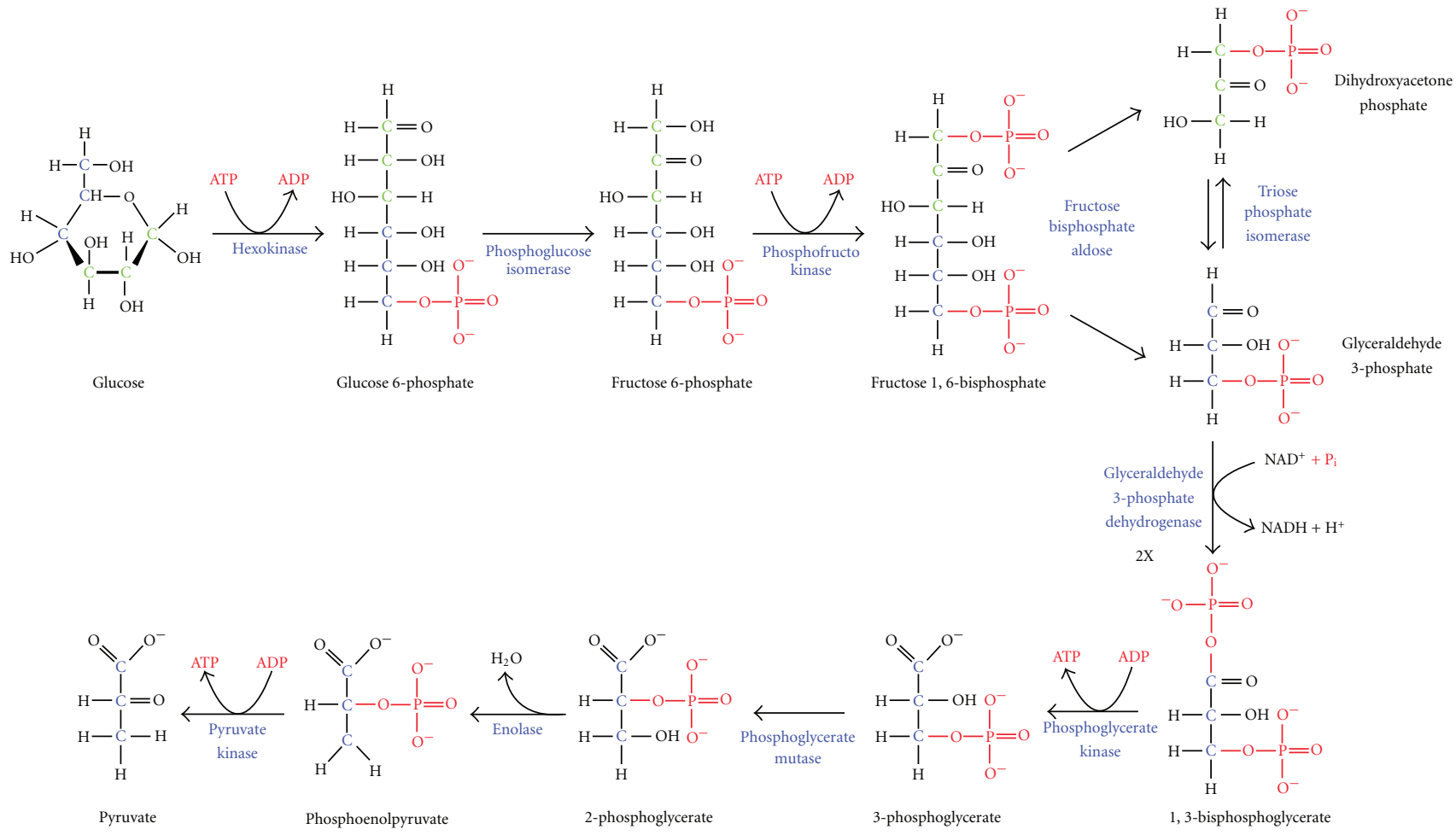

FIGURE 2: Schematic representation of glycolysis and its reaction with $\mathrm{AgNO}_{3}$ for production of AgNPs.

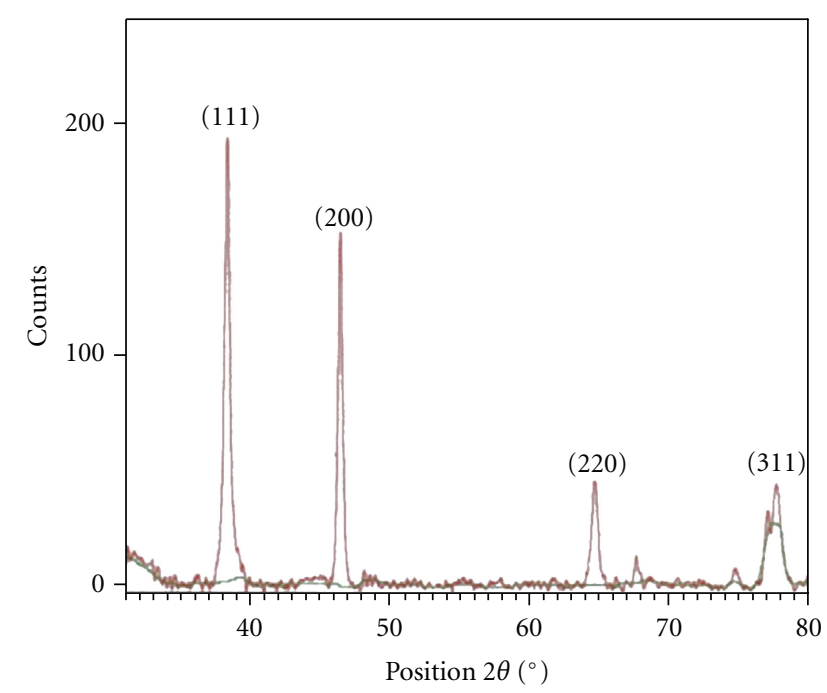

FIGURE 3: Room temperature X-ray diffractogram of silver nanoparticles.

$\mathrm{S}, \mathrm{P}$, and $\mathrm{N}$ correspond to the protein capping over the AgNPs. HRTEM images of Ag nanopatrticles derived from the plant extract are shown in Figure 5. The morphology of the NPs was predominantly spherical, and they appear to be monodisperse. Some of the NPs were found to be oval and/or elliptical. Such variation in shape and size of nanoparticles synthesized by biological systems is common.

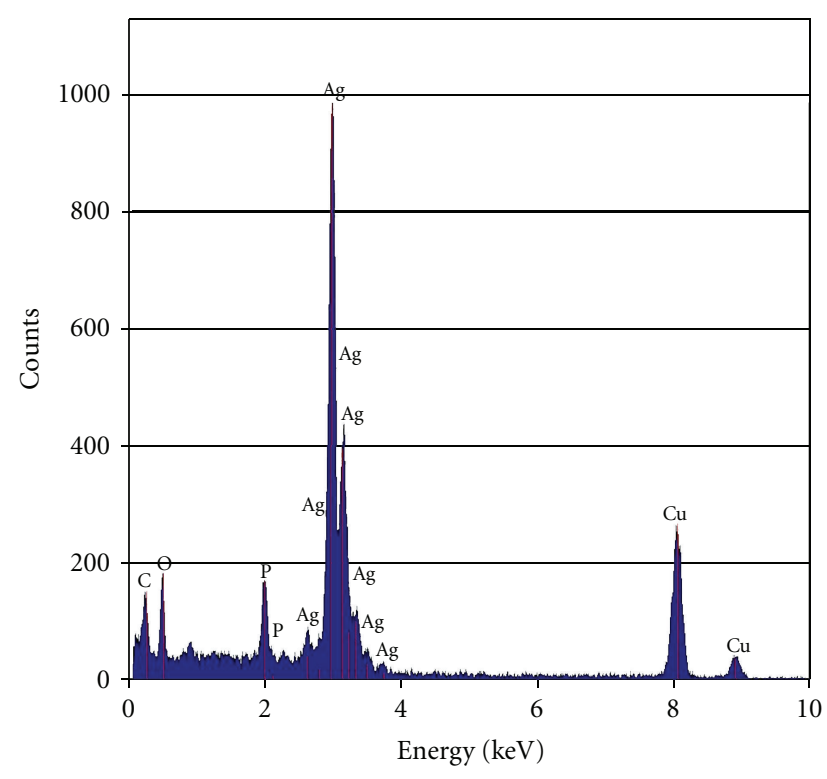

EDX bright field point 1

FIguRE 4: Energy-Dispersive Absorption Spectroscopy photograph of AgNPs.

It was noticeable that the edges of the particles were lighter than the centers, suggesting that biomolecules, such as proteins in Desmodium, capped the silver NPs. It is seen that proteins are present among the particles and are adhered to 


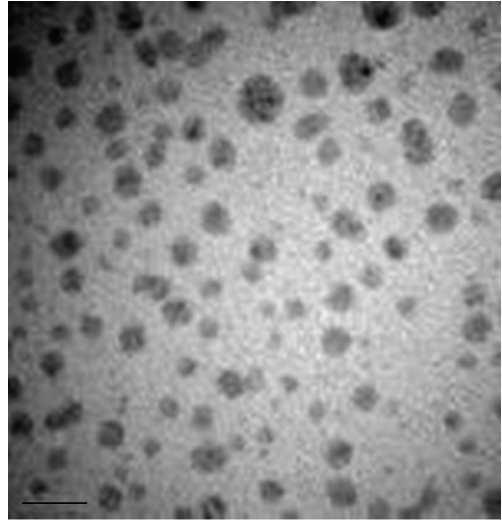

(a)

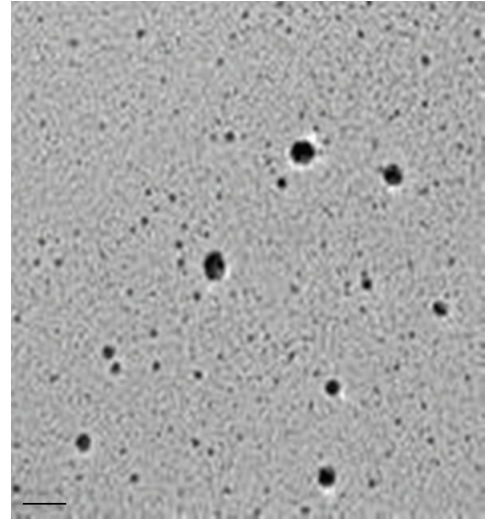

(b)

Figure 5: Transmission electron microscopy images of AgNPs at different magnifications.

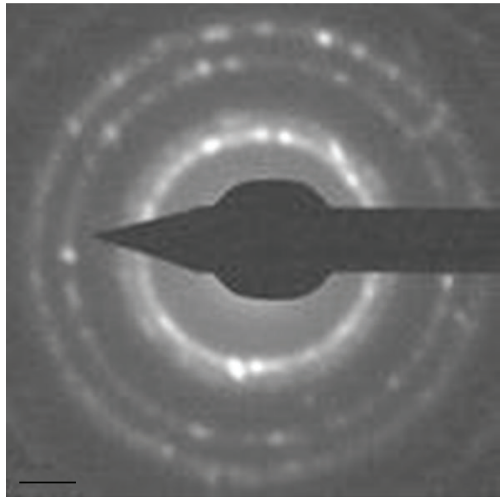

FIGURE 6: Selected area electron diffraction showing the characteristic crystal planes of elemental silver.

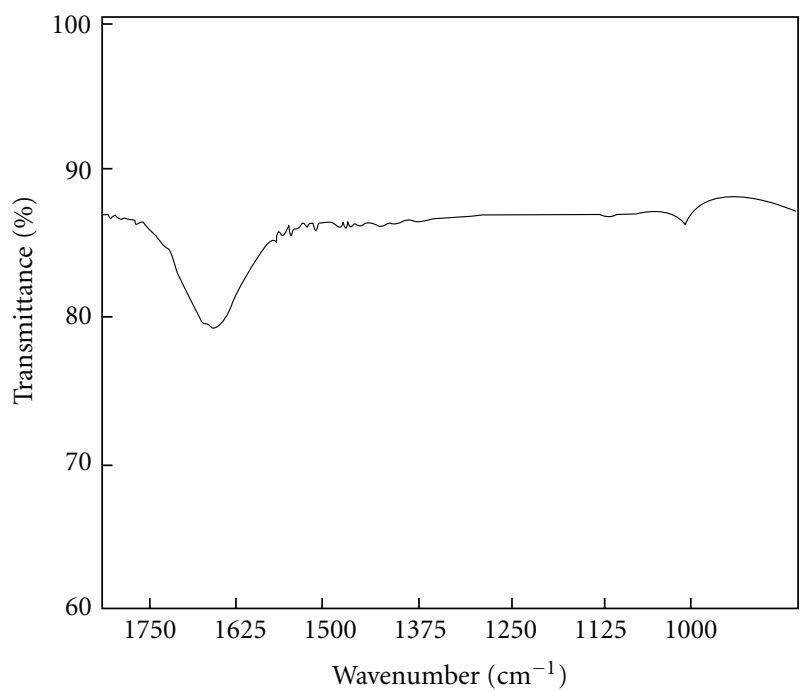

FIGURE 7: FTIR spectra of capped silver nanoparticles synthesized using Desmodium broth. their surfaces. These figures show NPs having a particle size in the range of $5-20 \mathrm{~nm}$. The silver particles are crystalline, as can be seen from the selected area diffraction pattern recorded from one of the nanoparticles in the aggregates (Figure 6).

FTIR measurements were carried out to identify the possible biomolecules responsible for the reduction of the $\mathrm{Ag}^{+}$ions and the capping of the bioreduced silver nanoparticles synthesized by the broth. The broth after complete reduction of $\mathrm{Ag}^{+}$was centrifuged at $12000 \mathrm{rpm}$ for 20 minutes to isolate the silver nanoparticles free from proteins or other compounds present in the solution. The representative spectra of nanoparticles obtained (Figure 7) manifest absorption peaks located at about 1030 and 1650, in the region $1000-1750 \mathrm{~cm}^{-1}$.

The absorption peak at around $1030 \mathrm{~cm}^{-1}$ can be assigned as absorption peaks of -C-O-C- or-C-O-. The peak at around $1650 \mathrm{~cm}^{-1}$ is assigned to the amide I bonds of proteins. The bonds or functional groups such as -C-O-C-,$\mathrm{C}-\mathrm{O}-$ and $-\mathrm{C}=\mathrm{C}$ - derived from heterocyclic compounds and the amide I bond derived from the proteins which are present in the extract are the capping ligands of the nanoparticles.

\section{Though the Bactericidal Effect of AgNPs is Now Well Established However the Mechanism is Only Partially Understood}

It has been reported that ionic silver strongly interacts with thiol group of vital enzymes and inactivates them [34-36]. Experimental evidence suggests that DNA loses its replication ability once the bacteria have been treated with silver ions [38]. The antibacterial effect of nanoparticles can be attributed to their stability in the medium as a colloid, which modulates the phosphotyrosine profile of the bacterial proteins and arrests bacterial growth.

Well diffusion assays were carried out to check the bactericidal activity of the silver nanoparticles they confirmed the antimicrobial activity of the AgNPs. The diffusion disk tests 
TABLE 1: Comparison of MIC values of AgNPs.

\begin{tabular}{lccc}
\hline Microorganisms & AgNPs $(\mu \mathrm{g} / \mathrm{mL})$ & Gentamiycin $(\mu \mathrm{g} / \mathrm{mL})$ & Active iodine $(\mu \mathrm{g} / \mathrm{mL})$ \\
\hline Staphylococcus spp (gram-positive bacteria) & 53 & 1255 & 1562 \\
Escherichia coli (gram-negative bacteria) & 27 & 1.2 & 1.5 \\
Bacillus subtilis & 54 & $<1.0$ & $<1.2$ \\
\hline
\end{tabular}

showed, in all the cases, a similar exclusion area that appears only around the nano Ag-discs. Most of the cultures were found to be inhibited in 14-25 $\mu \mathrm{g}$ of silver/mL. However, the multidrug resistant strains of staphylococcus and E.coli had highest MIC value of $57 \mu \mathrm{g}$ of silver/mL. No significant bacterial growth was observed at AgNPs concentrations above $75 \mu \mathrm{g} / \mathrm{mL}$.

After 24 hours, the presence of silver nanoparticles at a concentration of $14-60 \mu \mathrm{g} / \mathrm{cm}^{3}$ inhibited the bacterial growth by $62 \%$ and $88 \%$, respectively, while a concentration of $100 \mu \mathrm{g} / \mathrm{cm}^{3}$ caused $100 \%$ inhibition of bacterial growth. It was also observed that a combination of silver nanoparticles with antibiotics showed an approximate 2-fold increase in the MIC values.

The difference in the MIC zones of the different bacteria could be explained due to the presence of peptidoglycan, which is a complex structure and often contains teichoic acids or lipoteichoic acids which have a strong negative charge. This charge may contribute to the sequestration of free $\mathrm{Ag}^{+}$ions. Thus, gram-positive bacteria may allow less $\mathrm{Ag}^{+}$to reach the cytoplasmic membrane than the gram-negative bacteria. The studies revealed that there was synergistic effect when the antibiotic was combined with the silver nanoparticles in inhibiting the growth of organisms.

\section{Conclusion}

Stable and spherically shaped nanoparticles of average size $\sim 10 \mathrm{~nm}$ were synthesized using Desmodium plant. The green synthesis of AgNPs fulfills all the three main steps, which must be evaluated based on green chemistry perspectives, including (1) selection of solvent medium, (2) selection of environmentally benign reducing agent, and (3) selection of nontoxic substances for the AgNPs stability. The results showed that Ag nanoparticles presented good antibacterial performance against common pathogens. The nanoparticles when combined with the antibiotics show synergic effect in suppressing growth of antibiotics.

\section{Methods and Techniques}

Desmodium triflorum is a wild much branched slender diffused herb with trifoliate leaves occurring as small under herb found in grasslands, fields, and agricultural lands forming a green turf on the ground. It was uprooted, washed, and air dried. The entire plant was finely cut and pounded; $50 \mathrm{gms}$ was weighed to which $100 \mathrm{~mL}$ of distilled water was added. It was then heated at $60^{\circ} \mathrm{C}$ for 10 minutes. $5 \mathrm{~mL}$ of the source extract was added to $20 \mathrm{~mL}$ of 0.025 (M) $\mathrm{AgNO}_{3}$ solutions. The bioreduction of $\mathrm{Ag}^{+}$ions was monitored by periodic sampling. The $\mathrm{pH}$ of the sample was recorded and was found to be close to the $\mathrm{pH}$ of the plant broth $(\sim 7.88)$ thus indicating that there was not an appreciable change in the $\mathrm{pH}$ value of the cell extract and the plant broth.

The optical absorbance was recorded on UV-Vis spectrophotometer (Systronics 2202 double beam model) in 200-800 nm wavelength range. The solution containing the signatory color of AgNPs (dark brown) was then poured out into petri dishes and left in the oven for drying at $50^{\circ} \mathrm{C}$ for 24 hours. The formation and quality of compounds were checked by XRD technique. The X-ray diffraction (XRD) pattern measurements of drop-coated film of AgNPs on glass substrate were recorded in a wide range of Bragg angles $\Theta$ at a scanning rate of $2 \% \mathrm{~min}$, and was carried out on a Philips PW 1830 instrument that was operated at a voltage of $40 \mathrm{kV}$ and a current of $30 \mathrm{~mA}$ with $\mathrm{Cu} \mathrm{K} \alpha$ radiation (1.5405 $\AA$ ). High Resolution Transmission Electron Microscopy (HRTEM) was performed by TECHNAIG20-STWIN (200 KV) machine with a line resolution 2.32 (in angstrom). These images were taken by drop coating AgNPs on a carbon-coated copper grid. Energy Dispersive Absorption Spectroscopy photograph of AgNPs was carried out by the HR TEM equipment as mentioned above.

The purified powders of silver nanoparticles were subjected to FTIR spectroscopy measurement. These measurements were carried out on a Siemen sstr 2578564 instrument in the diffuse reflectance mode at a resolution of $4 \mathrm{~cm}^{-1}$ in $\mathrm{KBr}$ pellets. For comparison, a drop of $20 \%$ broth was mixed with $\mathrm{KBr}$ powder and pelletized after drying properly. The pellets were later subjected to FTIR spectroscopy measurement.

The antibacterial activity of the silver nanoparticles was evaluated by means of minimum inhibitory concentration value and antibacterial rate assays. The plates were incubated at $37^{\circ} \mathrm{C}$ for 24 hours. Each of the samples was done in six parallel experiments, and the average number of colonies was counted. The antibacterial rates were obtained from the calculation via the following equation:

$$
\text { Antibacterial rate }(\%)=\frac{N_{0}-N_{1}}{N_{0}} \times 100 \% \text {, }
$$

where $N_{0}$ and $N_{1}$ refer to the numbers of bacterium colonies in the control culture plates and the experiment culture plates, respectively.

Minimum Inhibitory concentration (MIC) of AgNPs was determined by the Muellar Hinton $(\mathrm{MH})$ broth by twofold serial dilution method. The concentration of the silver nanoparticles added to the first tube was $850 \mu / g$ silver/media tubes. The media tubes were inoculated with test cultures of three kinds of bacteria, that is, Escherichia coli 
(gram-negative bacteria), Staphylococcus epidermidis (grampositive bacteria), and Bacillus subtilis (spore bacteria) (106 $\mathrm{CFU} / \mathrm{mL}$ ) and incubated at $37^{\circ} \mathrm{C}$. Presence of the growth was visibly monitored after 48 hours of incubation.

Tubes in which no visual growth was observed were selected. $5 \mu \mathrm{L}$ of the content was inoculated on the $\mathrm{MH}$ agar plates. The absence of growth on the plates confirmed antibacterial activity. The MIC values of gentamicin and active iodine were determined in similar manner for comparison (Table 1).

\section{Acknowledgment}

The authors wish to acknowledge UGC for the financial support towards the Major Research Project.

\section{References}

[1] J. A. Dahl, B. L. S. Maddux, and J. E. Hutchison, "Toward greener nanosynthesis," Chemical Reviews, vol. 107, no. 6, pp. 2228-2269, 2007.

[2] J. E. Hutchison, "Greener nanoscience: a proactive approach to advancing applications and reducing implications of nanotechnology," ACS Nano, vol. 2, no. 3, pp. 395-402, 2008.

[3] P. T. Anstas and J. Warner, Green Chemistry: Theory and Practice, Oxford University Press, New York, NY, USA, 1998.

[4] L.-S. Li, J. Hu, and A. P. Alivistos, "Band gap variation of sizeand shape-controlled colloidal CdSe quantum rods," Nano Letters, vol. 1, no. 7, pp. 349-351, 2001.

[5] I. Hussain, M. Brust, A. J. Papworth, and A. I. Cooper, "Preparation of acrylate-stabilized gold and silver hydrosols and gold-polymer composite films," Langmuir, vol. 19, no. 11, pp. 4831-4835, 2003.

[6] A. M. Smith, H. Duan, M. N. Rhyner, G. Ruan, and S. Nie, "A systematic examination of surface coatings on the optical and chemical properties of semiconductor quantum dots," Physical Chemistry Chemical Physics, vol. 8, no. 33, pp. 3895-3903, 2006.

[7] G. J. Kearns, E. W. Foster, and J. E. Hutchison, "Substrates for direct imaging of chemically functionalized $\mathrm{SiO}_{2}$ surfaces by transmission electron microscopy," Analytical Chemistry, vol. 78, no. 1, pp. 298-303, 2006.

[8] A. K. Jha, K. Prasad, and A. R. Kulkarni, "Synthesis of $\mathrm{TiO}_{2}$ nanoparticles using microorganisms," Colloids and Surfaces B, vol. 71, no. 2, pp. 226-229, 2009.

[9] P. Mukherjee, A. Ahmad, D. Mandal et al., "Fungus-mediated synthesis of silver nanoparticles and their immobilization in the mycelial matrix: a novel biological approach to nanoparticle synthesis," Nano Letters, vol. 1, no. 10, pp. 515-519, 2001.

[10] S. Spring and K.-H. Schleifer, "Diversity of magnetotactic bacteria," Systematic and Applied Microbiology, vol. 18, no. 2, pp. 147-153, 1995.

[11] D. P. E. Dickson, "Nanostructured magnetism in living systems," Journal of Magnetism and Magnetic Materials, vol. 203, no. 1-3, pp. 46-49, 1999.

[12] D. Pum and U. B. Sleytr, "The application of bacterial S-layers in molecular nanotechnology," Trends in Biotechnology, vol. 17, no. 1, pp. 8-12, 1999.

[13] R. Joerger, T. Klaus, and C. G. Granqvist, "Biologically produced silver-carbon composite materials for optically functional thin-film coatings," Advanced Materials, vol. 12, no. 6, pp. 407-409, 2000.
[14] B. Nair and T. Pradeep, "Coalescence of nanoclusters and formation of submicron crystallites assisted by Lactobacillus strains," Crystal Growth and Design, vol. 2, no. 4, pp. 293-298, 2002.

[15] A. Ahmad, S. Senapati, M. I. Khan, R. Kumar, and M. Sastry, "Extracellular biosynthesis of monodisperse gold nanoparticles by a novel extremophilic actinomycete, thermomonospora sp," Langmuir, vol. 19, no. 8, pp. 3550-3553, 2003.

[16] C. W. N. Anderson, R. R. Brooks, R. B. Stewart, and R. Simcock, "Harvesting a crop of gold in plants," Nature, vol. 395, no. 6702, pp. 553-554, 1998.

[17] J. L. Gardea-Torresdey, E. Gomez, J. R. Peralta-Videa, J. G. Parsons, H. Troiani, and M. Jose-Yacaman, "Alfalfa sprouts: a natural source for the synthesis of silver nanoparticles," Langmuir, vol. 19, no. 4, pp. 1357-1361, 2003.

[18] J. Romero-González, J. C. Walton, J. R. Peralta-Videa, E. Rodríguez, J. Romero, and J. L. Gardea-Torresdey, "Modeling the adsorption of $\mathrm{Cr}$ (III) from aqueous solution onto Agave lechuguilla biomass: study of the advective and dispersive transport," Journal of Hazardous Materials, vol. 161, no. 1, pp. 360-365, 2009.

[19] V. Armendariz, J. G. Parsons, M. L. Lopez, J. R. Peralta-Videa, M. Jose-Yacaman, and J. L. Gardea-Torresdey, "The extraction of gold nanoparticles from oat and wheat biomasses using sodium citrate and cetyltrimethylammonium bromide, studied by $\mathrm{x}$-ray absorption spectroscopy, high-resolution transmission electron microscopy, and UV-visible spectroscopy," Nanotechnology, vol. 20, no. 10, Article ID 105607, 2009.

[20] S. P. Chandran, M. Chaudhary, R. Pasricha, A. Ahmad, and M. Sastry, "Synthesis of gold nanotriangles and silver nanoparticles using Aloe vera plant extract," Biotechnology Progress, vol. 22, no. 2, pp. 577-583, 2006.

[21] S. S. Shankar, A. Ahmad, and M. Sastry, "Geranium leaf assisted biosynthesis of silver nanoparticles," Biotechnology Progress, vol. 19, no. 6, pp. 1627-1631, 2003.

[22] M. Sathishkumar, K. Sneha, S. W. Won, C.-W. Cho, S. Kim, and Y.-S. Yun, "Cinnamon zeylanicum bark extract and powder mediated green synthesis of nano-crystalline silver particles and its bactericidal activity," Colloids and Surfaces B, vol. 73, no. 2, pp. 332-338, 2009.

[23] P. M. Tessier, O. D. Velev, A. T. Kalambur, J. F. Rabolt, A. M. Lenhoff, and E. W. Kaler, "Assembly of gold nanostructured films templated by colloidal crystals and use in surfaceenhanced Raman spectroscopy," Journal of the American Chemical Society, vol. 122, no. 39, pp. 9554-9555, 2000.

[24] Y. C. Cao, R. Jin, and C. A. Mirkin, "Nanoparticles with Raman spectroscopic fingerprints for DNA and RNA detection," Science, vol. 297, no. 5586, pp. 1536-1540, 2002.

[25] N. L. Rosi and C. A. Mirkin, "Nanostructures in biodiagnostics," Chemical Reviews, vol. 105, no. 4, pp. 1547-1562, 2005.

[26] J. Belloni, "Photography: enhancing sensitivity by silver-halide crystal doping," Radiation Physics and Chemistry, vol. 67, no. 3-4, pp. 291-296, 2003.

[27] M. Sanjappa, B. Singh, and M. P. Singh, Botanical Survey of India, 1992.

[28] A. Vedpriya, "Living Systems: eco-friendly nanofactories," Digest Journal of Nanomaterials and Biostructures, vol. 5, no. 1, pp. 9-21, 2010.

[29] O. Collera-Zúñiga, F. García Jiménez, and R. Meléndez Gordillo, "Comparative study of carotenoid composition in three mexican varieties of Capsicum annuum L," Food Chemistry, vol. 90, no. 1-2, pp. 109-114, 2005. 
[30] B. H. Jagadeesh, T. N. Prabha, and K. Srinivasan, "Improved shelf life of bell capsicum fruits by manipulation of the activities of glycosidases through heat," Indian Journal of Plant Physiology, vol. 9, no. 2, pp. 164-168, 2004.

[31] N. Ahmad, M. K. Alam, V. N. Singh, and S. Sharma, "Bioprospecting AgNPs from wild desmodium species," Journal of Bionanoscience, vol. 3, no. 2, pp. 97-104, 2009.

[32] V. K. Sharma, R. A. Yngard, and Y. Lin, "Silver nanoparticles: green synthesis and their antimicrobial activities," Advances in Colloid and Interface Science, vol. 145, no. 1-2, pp. 83-96, 2009.

[33] J. L. Elechiguerra, J. L. Burt, J. R. Morones et al., "Interaction of silver nanoparticles with HIV-1," Journal of Nanobiotechnology, vol. 3, article no. 6, 2005.

[34] A. D. Russell and W. B. Hugo, "Antimicrobial activity and action of silver," Progress in Medicinal Chemistry, vol. 31, pp. 351-370, 1994.

[35] H. Y. Lee, H. K. Park, Y. M. Lee, K. Kim, and S. B. Park, "Silver nanoparticles and its antibacterial evaluation for biomedical applications," Chemical Communications, vol. 28, p. 2885, 2007.

[36] S. H. Jeong, S. Y. Yeo, and S. C. Yi, "The effect of filler particle size on the antibacterial properties of compounded polymer/silver fibers," Journal of Materials Science, vol. 40, no. 20, pp. 5407-5411, 2005.

[37] T.-H. Wu, F.-L. Yen, L.-T. Lin, T.-R. Tsai, C.-C. Lin, and T.-M. Cham, "Preparation, physicochemical characterization, and antioxidant effects of quercetin nanoparticles," International Journal of Pharmaceutics, vol. 346, no. 1-2, pp. 160-168, 2008.

[38] S. Pal, Y. K. Tak, and J. M. Song, "Does the antibacterial activity of silver nanoparticles depend on the shape of the nanoparticle? A study of the gram-negative bacterium Escherichia coli," Applied and Environmental Microbiology, vol. 73, no. 6, pp. 1712-1720, 2007. 

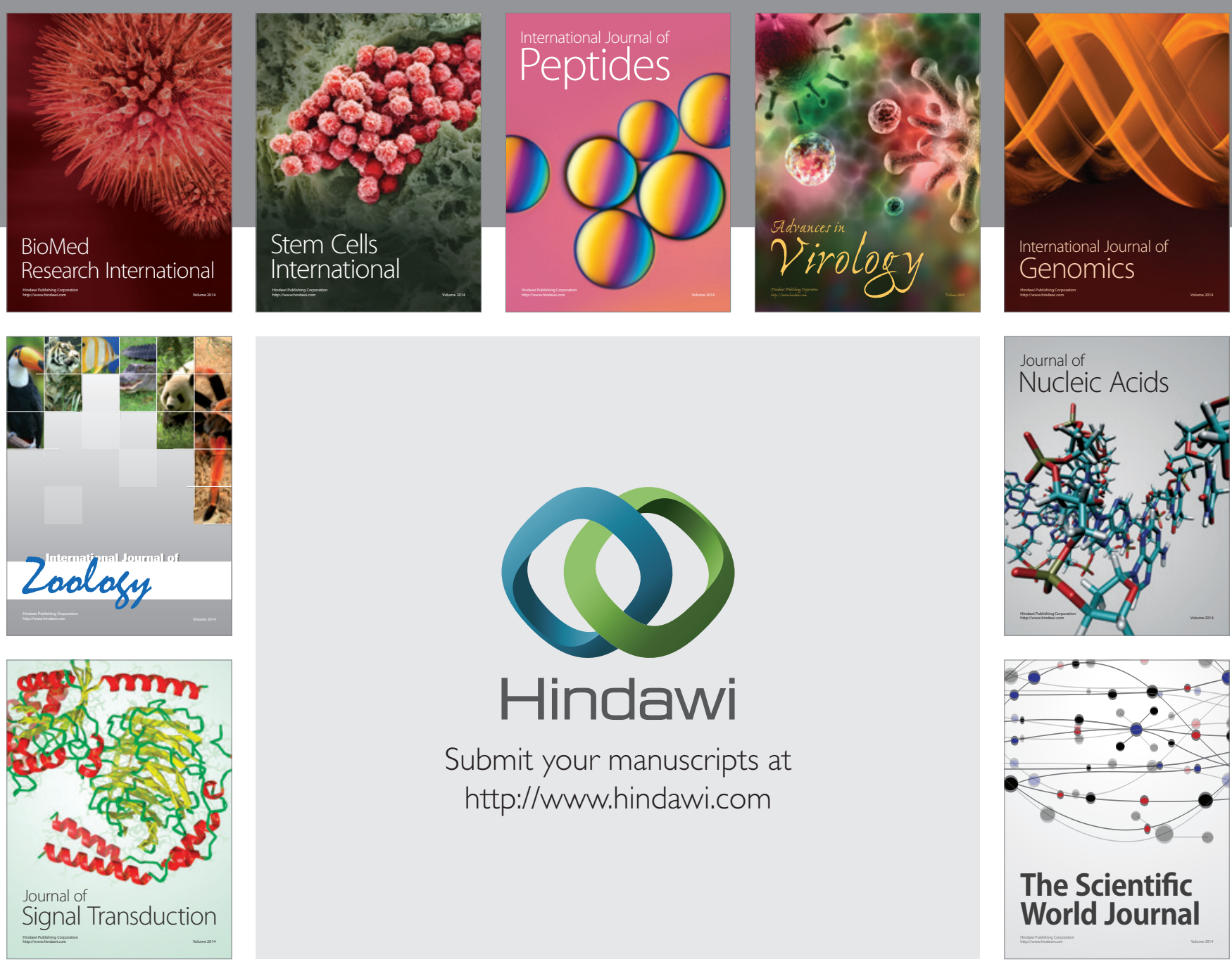

Submit your manuscripts at

http://www.hindawi.com
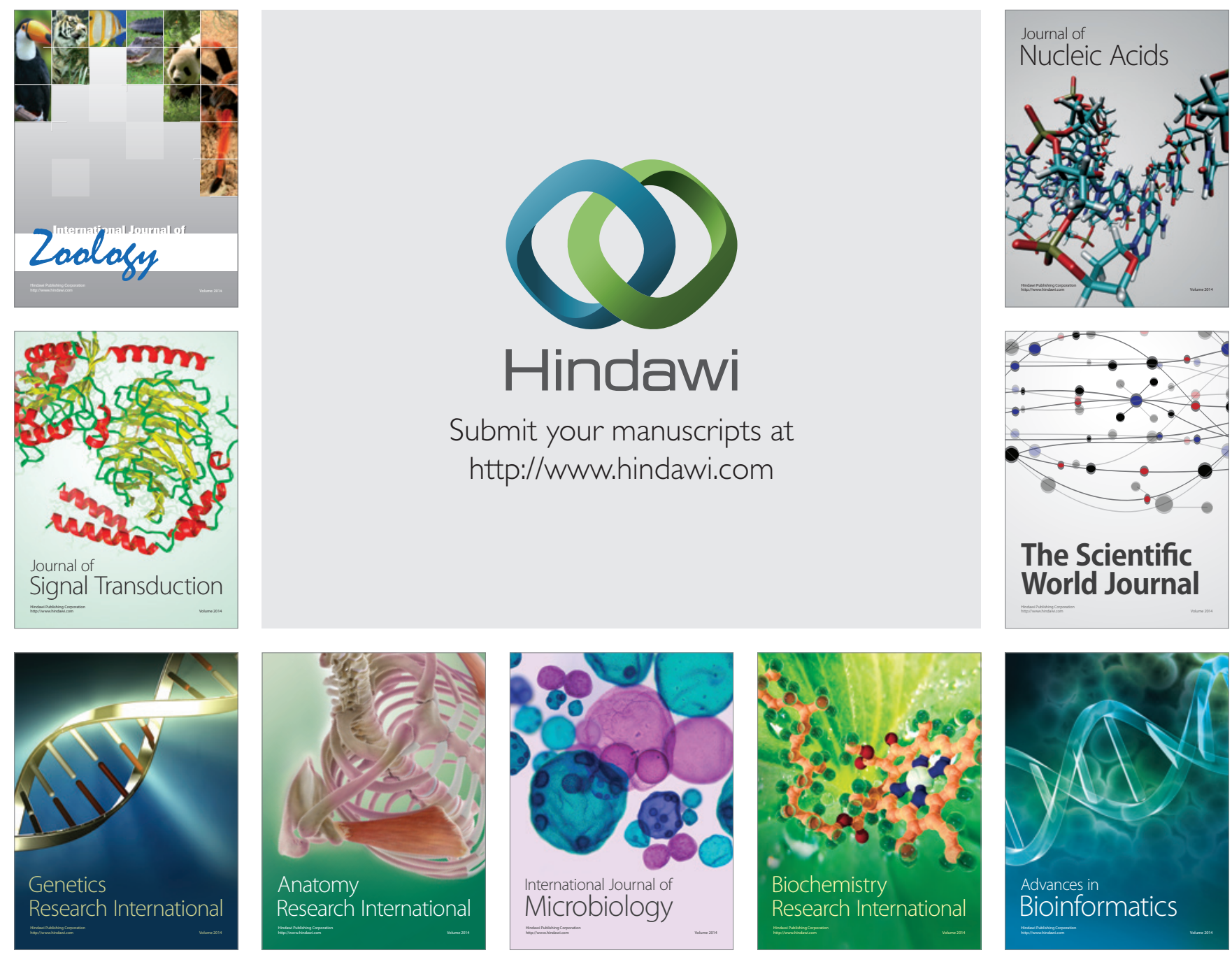

The Scientific World Journal
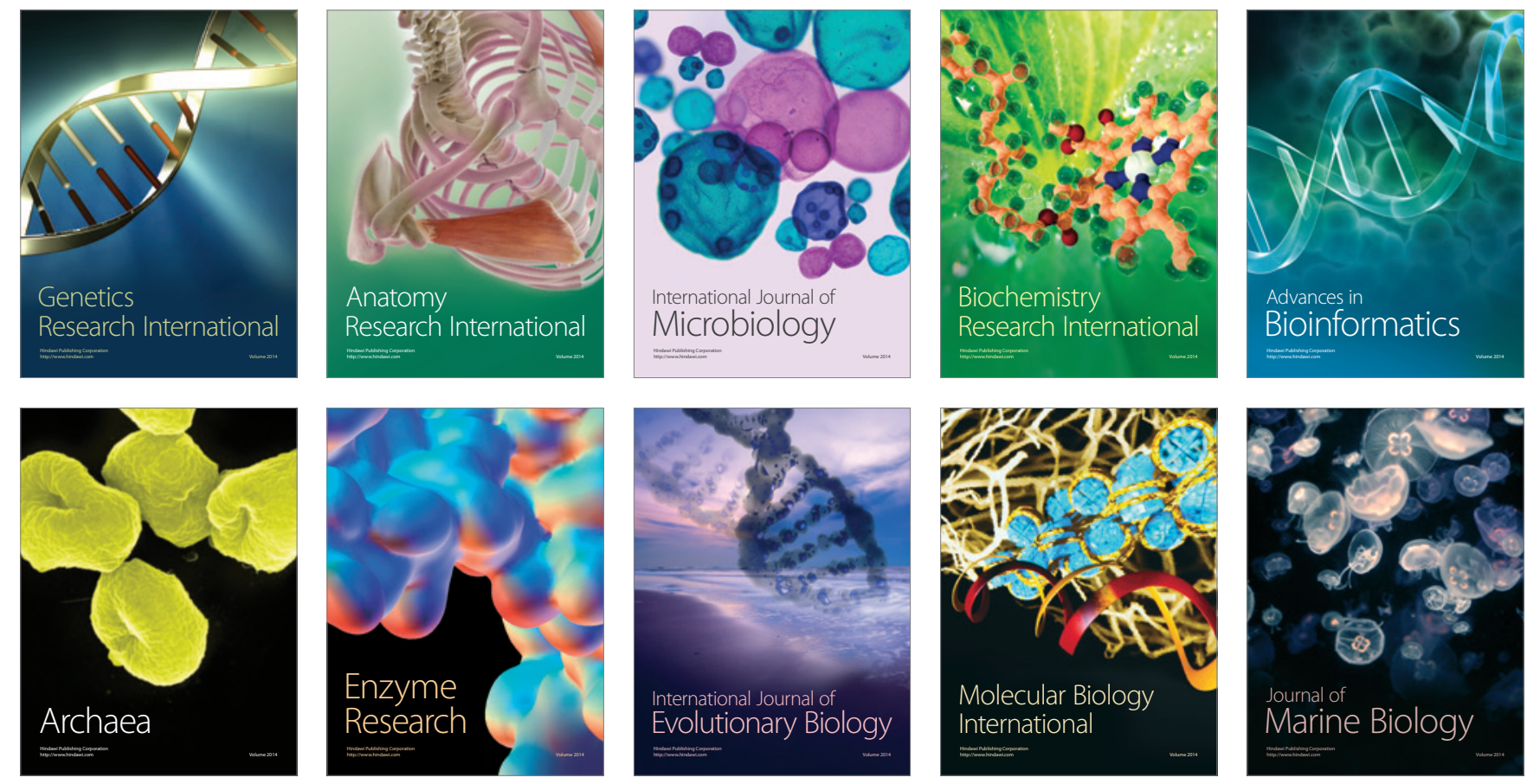